\title{
All we need is a cue to remember: The effect of an extinction cue on renewal
}

Citation for published version (APA):

Dibbets, P., Havermans, R. C., \& Arntz, A. R. (2008). All we need is a cue to remember: The effect of an extinction cue on renewal. Behaviour Research and Therapy, 46(9), 1070-1077.

https://doi.org/10.1016/j.brat.2008.05.007

Document status and date:

Published: 01/01/2008

DOI:

10.1016/j.brat.2008.05.007

Document Version:

Publisher's PDF, also known as Version of record

Document license:

Taverne

Please check the document version of this publication:

- A submitted manuscript is the version of the article upon submission and before peer-review. There can be important differences between the submitted version and the official published version of record.

People interested in the research are advised to contact the author for the final version of the publication, or visit the DOI to the publisher's website.

- The final author version and the galley proof are versions of the publication after peer review.

- The final published version features the final layout of the paper including the volume, issue and page numbers.

Link to publication

\footnotetext{
General rights rights.

- You may freely distribute the URL identifying the publication in the public portal. please follow below link for the End User Agreement:

www.umlib.nl/taverne-license

Take down policy

If you believe that this document breaches copyright please contact us at:

repository@maastrichtuniversity.nl

providing details and we will investigate your claim.
}

Copyright and moral rights for the publications made accessible in the public portal are retained by the authors and/or other copyright owners and it is a condition of accessing publications that users recognise and abide by the legal requirements associated with these

- Users may download and print one copy of any publication from the public portal for the purpose of private study or research.

- You may not further distribute the material or use it for any profit-making activity or commercial gain

If the publication is distributed under the terms of Article $25 \mathrm{fa}$ of the Dutch Copyright Act, indicated by the "Taverne" license above, 


\title{
All we need is a cue to remember: The effect of an extinction cue on renewal
}

\author{
Pauline Dibbets*, Remco Havermans, Arnoud Arntz \\ Clinical Psychological Science, Maastricht University, Maastricht, The Netherlands
}

\section{A R T I C L E I N F O}

\section{Article history:}

Received 5 November 2007

Received in revised form 13 May 2008

Accepted 20 May 2008

\section{Keywords:}

Context

Extinction cue

Retrieval

Exposure

Renewal

Conditioning

\begin{abstract}
A B S T R A C T
In the present study, it was investigated by employing a human fear conditioning paradigm whether an extinction retrieval cue can attenuate renewal of conditioned responding after an extinction treatment procedure, and if so, what the precise role of such an extinction cue comprises. It was hypothesized that such a cue can attenuate renewal and would function as a safety signal capable of directly inhibiting the expectancy of an aversive outcome and conditioned skin conductance responding to a conditioned stimulus. The results demonstrated that the extinguished expectancy of an aversive outcome was renewed when the CS was presented outside the extinction context and that an extinction cue attenuated this effect. This extinction cue, however, only transferred its inhibitory properties to other, nonextinguished stimuli when there was no contextual switch. This safety signal function was not observed after a switch in context. Possible functions of the extinction cue and its application in extinction-based exposure treatments are discussed.
\end{abstract}

(c) 2008 Elsevier Ltd. All rights reserved.

\section{Introduction}

Environmental cues play an important role in the expression of previously learned information. Several studies have demonstrated that recall of learned material is better if testing is conducted in the same context as present during learning than if it is conducted in another context. This context dependency has been frequently observed in both human (e.g., Dibbets, Maes, Boermans, \& Vossen, 2001; Shea \& Wright, 1995; Smith, 1988; Smith \& Vela, 2001) and animal conditioning studies (e.g., Hall \& Honey, 1989; Honey, Willis, \& Hall, 1990). Hall and Honey (1989), for example, demonstrated that rats that received paired presentations of a conditioned stimulus (CS) and unconditioned stimulus (US) in one context, showed a decline in responses to the CS when it was presented in a different context.

One type of learning that is specifically vulnerable to context changes is extinction (Bouton, 2004). During extinction the CS is presented without the US, leaving the CS with two available meanings regarding US (CS-US and CS-noUS). Depending on the context in which the CS is presented, one of the two available meanings is relatively more strongly retrieved from memory. One robust phenomenon indicating the ambiguous meaning of the CS is

\footnotetext{
* Corresponding author. Clinical Psychological Science, Maastricht University, UNS 50, P.O. Box 616, 6200 MD Maastricht, The Netherlands. Tel.: +31 4338815 97; fax: +31433884155 .

E-mail address: pauline.dibbets@dmkep.unimaas.nl (P. Dibbets).
}

the renewal effect (see for an overview Bouton, 2002, 2004). In this phenomenon, a change of context after extinction results in renewed responding to the CS, suggesting that the first-learned CSUS relation is retrieved. In the most common renewal paradigm, ABA-renewal, the acquisition of the CS-US relation takes place in one context (context A) and extinction is conducted in a separate context (context $\mathrm{B}$ ). When the CS is then presented in the original conditioning context (context $A$ ) renewed responding is observed.

Extinction-based treatment procedures, exposure therapies, are widely used in treating addictive behaviours (Drummond \& Glautier, 1994; Drummond, Tiffany, Glautier, \& Remington, 1995), specific phobias (Ost, 1997), posttraumatic stress disorder (see for a review Foa, Rothbaum, \& Furr, 2003), obsessive compulsive disorder (Abramowitz, 1996; Marks, Hodgson, \& Rachman, 1975) and other anxiety disorders. A typical exposure treatment involves repeated, non-reinforced presentations of stimuli, such as drugrelated cues or stimuli evoking a fear response, in order to extinguish responses to these stimuli. Although exposure therapy is highly effective, relapses do occur. Given what is known of animal extinction studies and learning theory, this can easily be explained. Learning of the CS-US relation has often occurred in an environment different from the exposure treatment context. Therefore, a switch in context after exposure treatment can lead to a renewed responding to the CS, thereby enhancing the probability of a relapse (see also Conklin \& Tiffany, 2002). Indeed, such renewal effects after exposure have been observed in spider fear (Mineka, Mystkowski, Hladek, \& Rodriguez, 1999; Mystkowski, Craske, \& Echiverri, 2002; 
Mystkowski, Mineka, Vernon, \& Zinbarg, 2003; Rodriguez, Craske, Mineka, \& Hladek, 1999), smoking (Thewissen, Snijders, Havermans, van den Hout, \& Jansen, 2006), and social drinking (Collins \& Brandon, 2002).

There are several ways to reduce a possible renewal effect after an extinction procedure or exposure therapy (see for an overview Bouton, 2002; Conklin \& Tiffany, 2002; Havermans \& Jansen, 2003). For example, renewal is attenuated when extinction is conducted in multiple contexts (Gunther, Denniston, \& Miller, 1998), or when an extinction retrieval cue is added during extinction. Especially, the latter method seems to be a promising candidate for generalizing extinction beyond the clinical exposure context. In a series of animal conditioning experiments, Brooks and Bouton (1994) demonstrated that presentation of a cue from extinction during renewal testing attenuated the renewal effect. The authors propose that this extinction cue helps to disambiguate the meaning of the CS during the renewal test by retrieving the memory of extinction. In animal research, such extinction cues have also been found to reduce spontaneous recovery of appetitive conditioned responding (Brooks \& Bouton, 1993, 1993), conditioned taste aversion (Brooks, Palmatier, Garcia, \& Johnson, 1999), and conditioned alcohol tolerance (Brooks, Vaughn, Freeman, \& Woods, 2004) after successful extinction. To our knowledge, only two studies have examined the effect of extinction cues on response recovery in humans. The first study is that of Collins and Brandon (2002). In their study social drinkers were exposed to alcohol cues and renewal of extinguished cue-elicited motivation to drink alcohol was tested in the same context as extinction, a different context, or a different context containing an extinction retrieval cue from the extinction context. The results indicated that, relative to the second group, the extinction cue at test attenuated renewed responding. However, this design does not allow for examining the influence of an extinction cue in a full ABA-renewal paradigm, because no control could be exerted on the acquisition of conditioned urges to drink alcohol. In the study of Vansteenwegen et al. (2006), employing a human fear conditioning procedure, a full ABA-renewal paradigm was used. The cue preceded the CSs either during the acquisition phase (context A), or during the extinction phase (context B). Testing was conducted in the acquisition context $(A)$ with the retrieval cue present. Renewal of conditioned fear responding was stronger for the group in which the cue previously preceded the CSs during acquisition than for the group in which the cue preceded the CSs during extinction. Although this study does indicate that renewal can be attenuated by the presence of a concurrent cue, the exact role of this stimulus remains unclear because no additional tests, such as a transfer or summation test, were conducted.

The primary aim of this study was to further explore the role of an extinction cue on renewal of conditioned fear responding in humans. In the present study, the extinction cue was not only presented before the onset of the CSs, but remained present throughout the entire extinction phase. The reason is that such a type of presentation can be readily applied in a clinical setting, with the cue coming to function as a safety signal (Drummond, Cooper, \& Glautier, 1990). A safety signal can be regarded as a so called conditioned inhibitor; it predicts the absence of the US. Such a safety signal can easily transfer its inhibitory properties to other CSs, extending its usefulness beyond the extinguished CS. In the absence of such transfer one would have to conclude that the extinction cue more likely functions as an occasion setter. Occasion setting refers to the ability of a cue to come to control responding to a CS by activating a representation of a specific CS-US relationship stored in memory (Holland, 1983). An occasion setting stimulus is thus not directly associated with the (non)occurrence of the US and animal research has shown that the occasion setting properties of a cue typically do not transfer to other CSs unless these stimuli have been part of an occasion setting discrimination procedure (e.g.,
Holland, 1989). If the extinction retrieval cue is endowed with occasion setting properties, one would have to conclude that the benefit of employing such a cue in exposure therapy is probably limited.

For the present study, it was hypothesized that an extinction cue should reduce renewed responding after a switch back to the acquisition context. Furthermore, it was hypothesized that the extinction cue acquires the properties of a safety signal, hence demonstrating transfer of direct inhibition to other non-extinguished CSs.

\section{Method}

\section{Participants}

Seventy-five psychology students (21 male, 54 female) aged $19-31$ years $(M=21.11$ years, $S D=1.68)$ participated and received $1 \mathrm{~h}$ of credit for their contribution. All participants signed a written informed consent before onset of the experiment, and they were randomly assigned to one of four experimental groups, with the restriction of an equal female/male distribution in each group.

\section{Apparatus}

Three different black geometric figures, a circle (diameter of 175 pixels), triangle (base of 175 pixels, height of 150 pixels), and square (length and height of 175 pixels), functioned as conditioned stimuli. A loud scream ( $2000 \mathrm{~ms}, 95 \mathrm{~dB}$, instantaneous rise time) was presented binaurally through headphones and served as a US (see also Hamm, Vaitl, \& Lang, 1989). Two of the CSs were consistently followed by the US (CS1+ and CS2+), the remaining stimulus was never paired with the US (CS3-). The CSs were presented against one of two different background colours, orange or blue. These colours functioned as context, and an ampersand-symbol, " $\&$ ", on the computer screen functioned as the extinction cue. The role of the stimuli was determined randomly for each participant with the restriction that each stimulus functioned at least once as CS1, CS2, and CS3. Only one version will be described for the remainder of the paper for sake of clarity. US-expectancy was measured in two ways: skin conductance response (SCR) and an online rating via a $100 \mathrm{~mm}$ visual analogue scale (VAS). Electrodermal activity was continuously recorded with $\mathrm{AgCl}$ electrodes (1 $\mathrm{cm}$ diameter) attached to the volar surfaces of the medial phalanges of the index and ring finger of the nondominant hand. All participants cleaned their hands with ordinary tap water prior to the attachment of the electrodes. A Picker Schwarzer Skin Conductor, EPA 48 conducted the signal to DSA-DAQ skin conductance software. In this experiment, a $500 \mathrm{~Hz}$ anti-aliasing filter was used.

The US-expectancy was measured on each trial by a visual analogue scale that was presented at the bottom of the screen below the stimuli and background. The indicator could be set anywhere between the far left (certainly no noise) and the far right end (certainly a noise) by clicking the left mouse button. The whole experiment was run on an IBM-compatible desktop computer and programmed with E-prime software (Psychology Software Tools, http://www.pstnet.com/).

\section{Procedure}

The participant was seated in a comfortable armchair in a sound attenuated experimental room. The experimenter was present in an adjacent room and verbal communication was possible through an intercom system.

The experiment consisted of an Acquisition phase, an Extinction phase, and one renewal test, Test A. Table 1 summarizes the experimental design. The four groups in this experiment were: 
ABAcue, ABAno cue, AAAcue, and AAAno cue. A and B symbolize the different contexts (orange and blue) during respectively the acquisition, extinction and Test A; cue indicates whether the extinction cue was present (cue) or absent (no cue) during the renewal Test A. The extinction cue was an ampersand ("\&") that was presented throughout the extinction phase for all four groups. For example, ABAno cue indicates that this group received the acquisition in context $A$, the extinction in context $B$ (plus extinction cue), and renewal Test $A$ was performed in context $A$ with no extinction cue present.

\section{Pre-conditioning}

After entering the experimental room, participants were seated in a comfortable armchair and the electrodes were attached. The experimenter started the experiment and an instruction screen appeared. In this instruction, the participants were encouraged to detect the contingencies between the pictures presented and the (non)occurrence of the loud noise. Furthermore, a brief instruction about the use of the visual analogue scale (VAS) was presented. Subsequently, the US and each of the CSs were presented. Participants were invited to rate each of the CSs with the VAS and to indicate whether the US was not too loud. The participants were told that the US should be loud and aversive, but not painful. If necessary, the volume of the US was adjusted on directions of the participant. This initial rating of the CSs was used to familiarize the participants with the use of the VAS. The experimenter checked if all instructions were clear and the participant was able to correctly use the VAS and then left the room.

\section{Acquisition phase}

The acquisition phase was identical for all four groups. During the entire phase the background colour remained orange. Below the background, a grey band at the bottom of the computer screen contained the VAS. At the extreme left of the VAS the text "certainly no noise" was displayed, at the extreme right the text "certainly a noise" was shown. The VAS was only displayed during the presentation of the CS; only responses during the CS were recorded. The CS was presented in the middle of the coloured background and remained visible for $6 \mathrm{~s}$. In case of CS1 and CS2, the US (2000 ms) was directly presented after the offset of the CS. CS3 was never followed by the US. The intertrial-interval varied between 14 and $16 \mathrm{~s}$. Each CS was presented 8 times, resulting in a total of 24 trials. CSs were pseudo randomly mixed with the restriction that a CS was never presented more than two times in a row, and UStrials were never presented more than four times in succession. After the last trial the next phase was automatically started.

Table 1

\begin{tabular}{|c|c|c|c|}
\hline Group & Acquisition & Extinction & Test A \\
\hline$\overline{\text { ABAcue }}$ & $\begin{array}{l}\mathrm{A}[\mathrm{CS} 1+] \\
\mathrm{A}[\mathrm{CS} 2+] \\
\mathrm{A}[\mathrm{CS} 3-]\end{array}$ & $\begin{array}{l}\mathrm{B}[\mathrm{CS} 1-] \text { cue } \\
\mathrm{B}[\mathrm{CS} 3-] \text { cue }\end{array}$ & $\begin{array}{l}\text { A[CS1]cue } \\
\text { A[CS2]cue } \\
\text { A[CS3]cue }\end{array}$ \\
\hline ABAno cue & $\begin{array}{l}\mathrm{A}[\mathrm{CS} 1+] \\
\mathrm{A}[\mathrm{CS} 2+] \\
\mathrm{A}[\mathrm{CS} 3-]\end{array}$ & $\begin{array}{l}\mathrm{B}[\mathrm{CS} 1-] \text { cue } \\
\mathrm{B}[\mathrm{CS} 3-] \text { cue }\end{array}$ & $\begin{array}{l}\mathrm{A}[\mathrm{CS} 1] \\
\mathrm{A}[\mathrm{CS} 2] \\
\mathrm{A}[\mathrm{CS} 3]\end{array}$ \\
\hline AAAcue & $\begin{array}{l}\mathrm{A}[\mathrm{CS} 1+] \\
\mathrm{A}[\mathrm{CS} 2+] \\
\mathrm{A}[\mathrm{CS} 3-]\end{array}$ & $\begin{array}{l}\text { A[CS1-]cue } \\
\text { A[CS3-]cue }\end{array}$ & $\begin{array}{l}\text { A[CS1]cue } \\
\text { A[CS2]cue } \\
\text { A[CS3]cue }\end{array}$ \\
\hline AAAno cue & $\begin{array}{l}\mathrm{A}[\mathrm{CS} 1+] \\
\mathrm{A}[\mathrm{CS} 2+] \\
\mathrm{A}[\mathrm{CS} 3-]\end{array}$ & $\begin{array}{l}\text { A[CS1-]cue } \\
\text { A[CS3-]cue }\end{array}$ & $\begin{array}{l}\mathrm{A}[\mathrm{CS} 1] \\
\mathrm{A}[\mathrm{CS} 2] \\
\mathrm{A}[\mathrm{CS} 3]\end{array}$ \\
\hline
\end{tabular}

Note: A and B represent the two different background colours, CS1, CS2, CS3 are the three different conditioned stimuli, + followed by the US, - no US. Cue means that the extinction cue is present. Testing was conducted without the US.

\section{Extinction phase}

For both the ABAcue and ABAno cue, the background colour switched to blue, for the AAAcue and AAAno cue the background colour remained orange for the entire extinction procedure. For all groups, CS1 and CS3 were presented 12 times each and no US followed. Stimulus order was pseudorandom with the restriction that a stimulus was not presented more than three times in succession. The extinction cue was presented during the complete extinction phase. The position of the cue varied across trials, but never overlapped the CS. Change in position occurred $7 \mathrm{~s}$ after offset of the CS, that is 7-9 s before onset of the next CS, in order to reduce attention and skin conductance effects by the position change. This procedure of repeated changes in position of the extinction cue was introduced to discourage configural learning and to enhance the salience of the extinction cue. After the last trial Test A was automatically presented.

\section{Test A}

All groups received Test $A$ in the orange acquisition context. For half of the groups the extinction cue was present, ABAcue and AAAcue, for the other half no cue was presented, ABAno cue and AAAno cue. The stimuli were presented in three 3-trial blocks; the order within a block was random. Further details were identical to that of the Extinction phase. After finishing the last trial, electrodes were removed and participants were requested to fill in a questionnaire regarding the valence of the CSs and US.

\section{Ratings stimuli}

After the electrodes were removed, the participants received a questionnaire with questions concerning the CSs and US. For each of the three geometrical figures, participants had to rate its (un)safety and (un)pleasantness on separate VASs. Finally, they had to indicate the perceived (un)pleasantness of the US at the onset of the experiment and whether this (un)pleasantness changed across US presentations (i.e., less unpleasant or more unpleasant).

\section{Criteria}

Only the data of participants that mastered the task were used for data analysis. Performance was labelled successful if both the acquisition and extinction phase fulfilled the following criteria: (1) on the last acquisition trial scores on the VAS scales for CS1 and CS2 needed to be at least $80 \%$, indicating clear expectancy of the US; (2) scores on the last acquisition trial of CS3 needed to be $20 \%$ or less, indicating that no US was expected; and (3) on the last extinction trial both CS1 and CS3 ratings should be $20 \%$ or less, indicating successful extinction. These criteria were used as testing for potential renewal is redundant in the absence of adequate extinction and examining extinction too becomes redundant in the absence of clear acquisition.

\section{Response definition and data reduction of SCR}

\section{Ratings and renewal}

The amount of renewal was calculated by subtracting the ratings of CS1 on the last extinction trial, trial 12, from the ratings on the first trial of Test A. A similar difference score was calculated for CS3. For CS2 the difference between the first Test A trial and last CS2 acquisition trial was calculated.

\section{Skin conductance responses}

Skin conductance responses (SCR) to the conditioned stimuli were scored as the largest increase in conductance between 900 and $4000 \mathrm{~ms}$ after stimulus onset (First Interval Response, FIR) using the computer programme Skin Conductance Analyser (version 10.40). Each pulse was visually examined and, if necessary, on- and offset were manually adjusted. Trials in which no response 
was observed or with negative changes were scored as zero and included in all analyses. Amplitudes were range corrected using the largest response on US only presentations during the pre-conditioning phase (Lykken \& Venables, 1971). The corrected amplitudes (i.e., the means used for analysis) were subjected to a square root transformation for normalization.

For each participant, mean amplitudes on the $\mathrm{CS} 1+, \mathrm{CS} 2+$, and CS3- were calculated for 6 blocks of 3 trials: the first three acquisition trials (acq1), the last three acquisition trials (acq2), the first three and last three extinction trials for CS1 and CS3 (ext1 and ext2, respectively), and, for all stimuli, the three test trials of test $A$ (test A). For calculation of the renewal (difference) score of these mean SCRs see Ratings and renewal.

\section{Statistical analyses}

Both the US-expectancy ratings on the VAS and SCR were analyzed using parametric tests. Bonferroni corrections were used by adjusting the rejection criterion in case of multiple pairwise comparisons. In case of violations of sphericity, GreenhouseGeisser corrections were made. Possible differences between groups in the distribution of gender and handedness were analyzed nonparametrically. Furthermore, the effect size of cue and context switch on renewal was calculated by means of the partial eta squared. The standard rejection criterion was set at $p<0.05$ throughout.

\section{Results}

The data from 11 participants were discarded from data analyses. Ten of these participants were excluded because they did not meet the aforementioned criteria for successful acquisition and one because of unsuccessful extinction. The remaining 64 participants were 19 males and 45 females $\left(M_{\text {age }}=21.3\right.$ years; $\left.S D=1.9\right)$. The number of participants per group was: ABAcue $n=17$; AAAno cue $n=15$; AAAcue $n=16$; ABAno cue $n=16$. No differences between the four experimental groups concerning age, $F(3,63)=1.13$, $p=0.34$, gender, or handedness were detected, $\chi^{2}<4.31, p s>0.23$.

\section{US-expectancy ratings}

\section{Acquisition}

The mean expectancy ratings of CS1, CS2, and CS3 are presented at the on the left side of Fig. 1. A GLM repeated measures with stimulus type (CS1, CS2, and CS3) and trial (1 through 8) as withinsubjects factors and group (AAAcue, AAAno cue, ABAcue, and ABAno cue) as between-subjects factors was used to analyze the expectancy ratings of the acquisition phase. This analysis revealed a main effect of stimulus, $F(1.39,83.62)=1062.84, p<0.001$, a main effect of trial, $F(3.32,199.23)=87.26, p<0.001$, but no main effect of group $F<1$. Pairwise comparisons revealed that the ratings of CS1 and CS2 differed from CS3, $p s<0.001$, but not from each other, $p=0.10$. Only the stimulus type $\times$ trial interaction yielded a significant effect, $F(6.76,405.43)=88.51, p<0.001$. This interaction was caused by the gradual increase of CS1 and CS2, Fs $>90.95$, $p s<0.001$, and the decrease in ratings of CS3, $F(3.97$, $237.95)=18.81, p<0.001$. No other interactions were observed, Fs $<1.52$, ps $>0.13$. These results indicate that, as expected, in all groups, the US-expectancy ratings after presentation of CS1 and CS2 increased across trials, whereas the expectancy ratings on presentation of CS3 gradually decreased.

\section{Extinction}

The ratings of CS1 and CS3 during the extinction phase are depicted on the right side of Fig. 1. As can be inferred from Fig. 1, the US-expectancy ratings of CS1 for the first extinction trial appear to be somewhat smaller than at the final acquisition trial. This suggests some generalization decrement. To test for potential generalization decrement a GLM repeated measures ANOVA was conducted with trial (acquisition trial 8 versus extinction trial 1) as within-subjects factor and group as between-subjects factor. A main effect of trial was found, $F(1,60)=20.02, p<0.001$, indicative of generalization decrement, but no effect of group, $F(3,60)=1.21, \quad p=0.32$, and no trial $\times$ group interaction, $F(3,60)=1.34, p=0.27$. Similarly, US-expectancy ratings for CS3 appear to change (i.e., increase) with the transition from acquisition to extinction phase. Therefore, a similar GLM repeated measures analysis was conducted for the CS3 ratings. Again, a clear effect of trial was found, $F(1,60)=125.18, p<0.001$, but no effect of group and no trial $\times$ group interaction, $F s<1.29$. As for all participants the extinction phase was marked by the presence of the extinction cue, it appears that the participants noticed this transition in experimental phase and this led to uncertainty regarding the expectation of the US in the presence of CS1 and CS3.

A repeated measures GLM was used to further analyze the extinction ratings. Stimulus (CS1 and CS3) and trial (1 through 12) served as within-subjects factors and group as between-subjects factor. This analysis revealed a main effect of stimulus, $F(1$, $60)=102.65, p<0.001$, a main effect of trial, $F(4.51$, $270.77)=180.75, p<0.001$, but no main effect of group or group interactions were detected, $F s<1.52, p s>0.20$. Furthermore, a stimulus $\times$ trial interaction was observed, $F(4.26,255.45)=26.04$, $p<0.001$. This interaction was caused by the initial differences between CS1 and CS3 at the first trial of the extinction phase, $F(1$, $60)=25.11, p<0.001$, resulting in a sharper decrease in ratings of CS1 than of CS3. Note that this also implies that the apparent uncertainty concerning the expectation of the US in the presence of CS1 and CS3 with the transition from acquisition to extinction clearly did not abolish the previously acquired differential expectancy ratings. No difference between the two stimuli was detected on the last extinction trial, $F(1,60)=1.33, p=0.25$. These results indicate that the extinction of CS1 was successful.

\section{Test A}

The mean ratings of CS1, CS2, and CS3 on the first test trial of Test $A$ are depicted in Fig. 2. The amount of renewal for CS1 was calculated by subtracting ratings on the last extinction trial from the first Test A trial. A univariate ANOVA with this difference score as dependent variable and cue (cue groups versus no cue groups) and context switch (AAA groups versus ABA groups) as factors was carried out. This analysis revealed both a significant effect of cue, $F(1,60)=23.49, p<0.001$, and of context switch, $F(1,60)=31.53$, $p<0.001$, but no cue $\times$ context switch interaction, $F(1,60)=1.38$, $p=0.24$. Both the absence of a cue and a switch in context resulted in more renewal, with both a large effect size of 0.28 and 0.34 , respectively. ${ }^{1}$ Pairwise comparisons of the groups revealed that the AAAcue group showed less renewal than the other groups, ps $<0.001$. Furthermore, the AAAno cue group showed less renewal than did the ABAno cue group, $p s<0.01$. Finally, the ABAcue group showed less renewal than did the ABAno cue group, $p s<0.05$. The amount of renewal can be summarized as follows: ABAno cue $>$ ABAcue $=$ AAAno cue $>$ AAAcue.

A similar analysis was run for the CS3 difference score. Only a significant effect of context switch was detected, $F(1,60)=11.23$,

\footnotetext{
${ }^{1}$ As the ratings for CS3 also seem to increase at test in some of the groups, we also calculated the difference between CS1 and CS3 ratings within each participant for the final extinction trial and the first Test A trial. Next, we calculated the contrast between these two difference scores and used this contrast as dependent variable in a cue $\times$ context switch univariate ANOVA. This analysis renders the same pattern of results.
} 


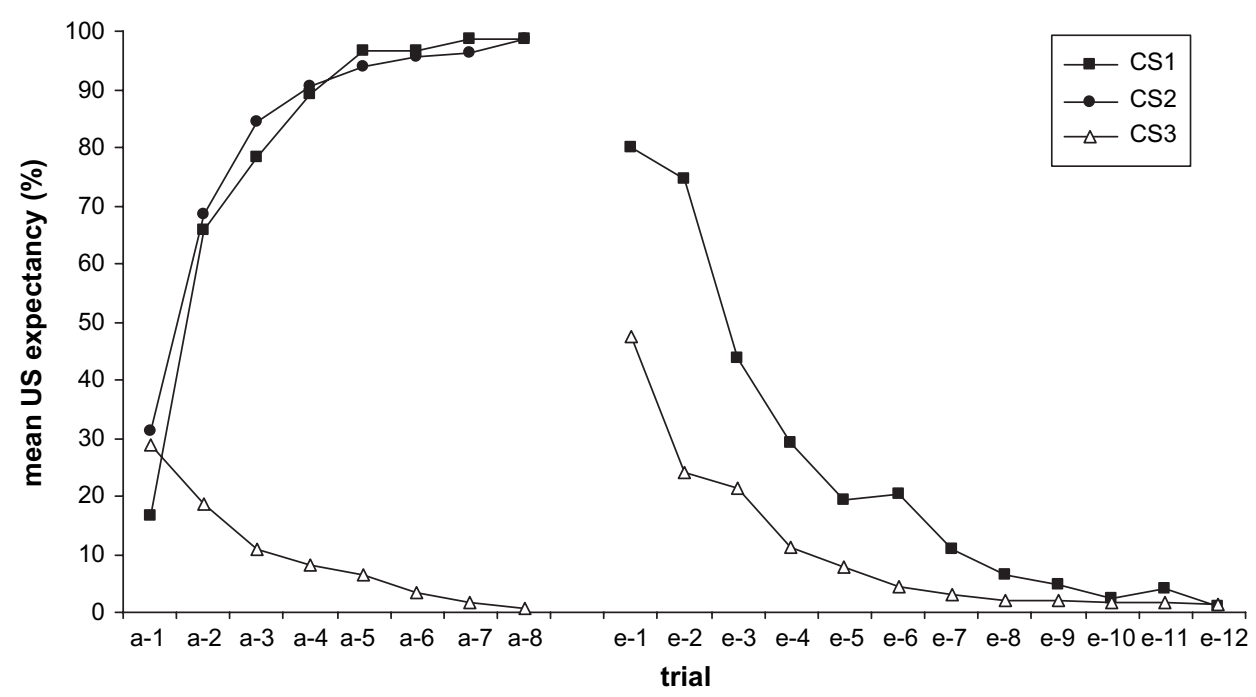

Fig. 1. Acquisition of the CS1, CS2, and CS3 expectancy ratings (trials a-1 through a-8), and extinction of the CS1, and CS3 expectancy ratings (trials e-1 through e-12).

$p<0.005$. No significant effect of cue was observed, $F(1,60)=2.96$, $p=0.09$, although the direction of the effect was towards lower ratings when the cue was present. Furthermore, no interaction between cue and context was observed, $F<1$. The observed effect size for a switch in context was large, with a partial eta squared of 0.16 . Pairwise comparisons of the groups revealed lower ratings of CS3 (relative to the last extinction trial) for the AAAcue group than for the ABAcue and ABAno cue groups, $p s<0.01$.

Finally, the influence of a cue and switch in context on CS2 responding was examined. The difference score was calculated by subtracting the last CS2 acquisition trial ratings from the first Test A trial. If the cue indeed served as the preferred safety signal, less responding on CS2 in the cue than no cue groups was expected. Once more a univariate ANOVA was run with the difference score as dependent variable and cue and context switch as factors. This analysis revealed a trend towards a significant effect of cue, $F(1$, $60)=3.70, p=0.059$, but not of context switch, $F<1$. Furthermore, a significant cue $\times$ context switch interaction was detected, $F(1$, $60)=4.51, \quad p<0.05$. Pairwise comparisons revealed that this interaction was caused by a difference in ratings, relative to the last acquisition trial, between the AAAcue group and AAAno cue group, $p<0.05$, that was not observed between the ABAcue and ABAno

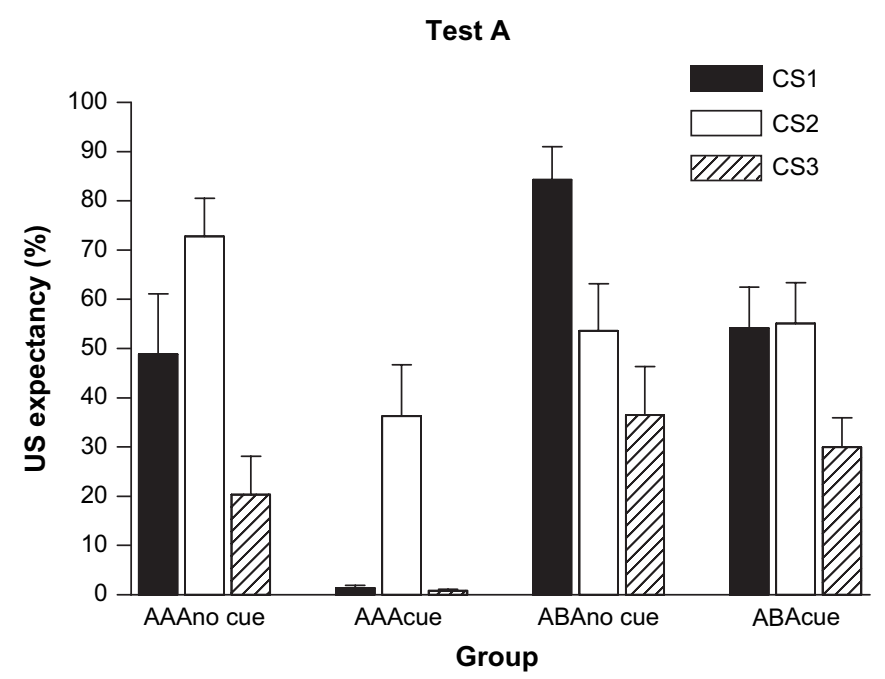

Fig. 2. The mean ratings of CS1, CS2, and CS3 on the first test trial of Test A. cue group, $p=1.00$. The pairwise comparisons revealed no other group differences, all $p s>0.75$.

Skin conductance response

The SCR data of two participants were not recorded due to equipment failure (one of the ABAcue and one of the ABAno cue group). Therefore, a total of 62 was included for SCR analyses.

\section{Acquisition}

A repeated measures GLM with stimulus type (CS1, CS2, and CS3) and trial block (block 1 and block 2) as within-subjects factors and group (AAAcue, AAAno cue, ABAcue, and ABAno cue) as between-subjects factors was used to analyze the SCR of the acquisition phase. This analysis revealed a main effect of trial block, $F(1,56)=8.54, p<0.01$, but no main effect of stimulus type, $F(1.39$, $77.95)=1.71, \quad p=0.19, \quad$ group $F(3,56)=1.56, \quad p=0.21$, or interactions, $F s<2.02$, $p s>0.12$. Especially, the absence of stimulus $\times$ trial block interaction was contrary to our expectations. Furthermore, a decrease rather than increase in SCR was observed for all stimuli, indicating that acquisition was not successful. Planned comparisons of CS1, CS2, and CS3 of the last acquisition block revealed no significant differences between these stimuli, $p s>0.19$. Given the absence of successful acquisition of differential conditioned SCR, no further analyses concerning extinction and renewal were conducted.

\section{Ratings of the stimuli}

\section{Pleasantness}

The mean ratings and accompanying standard errors of each stimulus are presented in Table 2. A repeated measures GLM was used to assess the pleasantness of CS1, CS2, and CS3. The stimuli functioned as within-subjects factor and group (AAAcue, AAAno cue, ABAcue, and ABAno cue) served as between-subjects factors. This analysis revealed a main effect of stimulus, $F(1.63$, $97.58)=58.38, p<0.001$, but no main effect of group or stimulus $\times$ group interaction was observed, $F s<1$. Pairwise comparisons revealed that CS3 was rated as more pleasant than were CS1 and CS2, $p s<0.001$, and that CS1 was rated as more pleasant than was CS2, $p<0.05$. The pleasant ratings can be ordered from more pleasant to less pleasant as: $\mathrm{CS} 3>\mathrm{CS} 1>\mathrm{CS} 2$. 
Table 2

Mean ratings of the stimuli used

\begin{tabular}{|c|c|c|c|c|c|c|c|c|}
\hline \multirow[t]{2}{*}{ Group } & \multicolumn{2}{|l|}{ CS1 } & \multicolumn{2}{|l|}{$\mathrm{CS} 2$} & \multicolumn{2}{|l|}{ CS3 } & \multicolumn{2}{|c|}{ US pleasant } \\
\hline & Pleasant & Safe & Pleasant & Safe & Pleasant & Safe & Start & End \\
\hline$\overline{\text { ABAcue }}$ & $38.82(6.1)$ & $30.41(4.2)$ & $37.35(6.2)$ & $31.53(4.4)$ & $76.29(5.4)$ & $83.59(3.6)$ & $5.94(1.5)$ & $48.12(7.6)$ \\
\hline ABAno cue & $36.06(6.1)$ & $33.63(4.9)$ & $30.13(5.5)$ & $35.06(5.7)$ & 74.13 (4.7) & $71.31(5.5)$ & $8.25(3.2)$ & $45.25(7.4)$ \\
\hline AAAcue & $43.88(5.4)$ & $43.63(7.3)$ & $35.38(5.8)$ & $49.00(7.4)$ & $67.06(6.4)$ & $70.63(7.7)$ & $8.94(3.3)$ & $38.88(6.9)$ \\
\hline AAAno cue & $47.80(6.6)$ & $42.20(5.1)$ & $37.07(4.8)$ & $36.00(3.8)$ & 76.53 (4.7) & $74.93(6.3)$ & $8.33(2.3)$ & 37.20 (7.0) \\
\hline
\end{tabular}

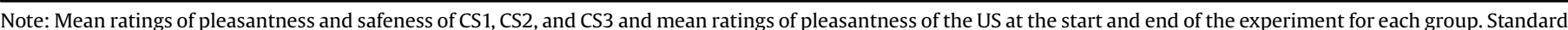

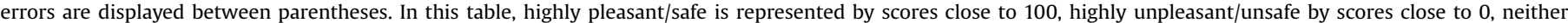
pleasant/safe nor unpleasant/safe is represented by scores around 50 .

\section{Safety}

The safety data were analyzed in the same way as the pleasantness ratings. The analysis revealed a main effect of stimulus, $F(1.40,83.75)=63.11, p<0.001$, but no effect of group, $F<1$, or stimulus $\times$ group interaction, $F(4.18,83.75)=1.77, p=0.14$. Pairwise comparisons revealed that CS3 was rated as more safe than CS1 and CS2, ps $<0.001$; no difference between the safety ratings of CS1 and CS2 was detected, $p=1.00$. The safety ratings can be ordered from more safe to less safe as: CS3 $>$ CS2 $=$ CS1.

\section{US ratings}

The US pleasantness ratings were analyzed with a repeated measures GLM. In this analysis, time (start experiment, end experiment) served as within-subjects factor and group (AAAcue, AAAno cue, ABAcue, and ABAno cue) functioned as between-subjects factor. This analysis revealed a main effect of time, $F(1,60)=71.27$, $p<0.001$, but no main effect of group or time $\times$ group interaction, $F s<1$. Compared to the start of the experiment, the US was rated as less unpleasant, indicating that the participants habituated to the US.

\section{Discussion}

In the present experiment, it was tested whether an extinction retrieval cue attenuates a renewal effect. The results indicate that the participants readily learned to differentiate between the CSs that predict the occurrence of the US (i.e., CS1 and CS2) and the CS that predicts the absence of the US (i.e., CS3). The resulting differential US-expectancy between CS1 and CS3 was successfully extinguished in the subsequent extinction treatment phase. At test, this differential US-expectancy was renewed when the test context differed from the extinction context. More importantly, such a renewal effect was diminished when the extinction cue was present reminding the participants of the preceding extinction treatment. The effect of the extinction cue and the context were additive, with similar large effect sizes.

Next to ability of an extinction cue to reduce renewed responding at test, a second aim of the present study was to investigate the precise role of such a cue. To this end it was tested whether the extinction cue would also be able to decrease the expectancy of the US in the presence of CS2 that had not underwent extinction. If the extinction cue during extinction would have acquired a direct inhibitory associative value (i.e., function as a safety signal), one would expect to observe a decrease in the USexpectancy of CS2. Such an effect was observed, but only among the participants who had received the extinction treatment in context A. When extinction had been conducted in context $B$, the extinction retrieval cue specifically decreased the US-expectancy of CS1, not that of CS2. The latter finding indicates that with a context switch from acquisition to extinction, the extinction cue appears to function as an occasion setter. In the present experiment, for groups ABAcue and ABAno cue, the participants learned that the extinction cue signals that specifically CS1 will not be followed by the US. Note that this particular result corresponds with the results obtained by
Brooks and Bouton (1994) in rats. They too found that the extinction retrieval cue can attenuate renewal of conditioned responding and that this cue does not appear to have acquired a direct inhibitory associative value (see also Brooks \& Bowker, 2001).

An alternative explanation for the diverging effect of the extinction cue on CS1 and CS2 for the ABA groups, can be found in the low CS2 ratings at test of the ABAno cue group. Instead of the expected value of "certainly a noise", CS2 was rated around the value of "uncertainty". Although this does not really represent a floor effect, it may be that a shift from "uncertainty" towards "certainly no noise" is more difficult to accomplish than a shift from "certainly a noise" towards "uncertainty". If this is the case, evaluation of the power by comparing the CS1 plus cue with the CS2 without this cue, which should represent the initial level of conditioned expectancy, reveals little or no effect of the cue.

An additional remark on the efficacy of the extinction cue is that one can argue that presentation of the cue did not attenuate CS1 renewal, but simply cancelled out the augmentation of renewal through removal of the extinction cue at test. In order to exclude this possibility an ABA control group without any cues present during extinction and test should be incorporated in future experiments.

The results of the skin conductance responses are more difficult to interpret. No adequate acquisition of differential condition skin conductance responding (SCR) was observed. The most likely explanation for this absence of differential SCR is habituation to the US. Although the US was considered aversive at the start of the experiment, the repeated exposure to the US during acquisition apparently led to rapid habituation to the US, expressed as decreasing skin conductance responding throughout the acquisition phase. Further indication for this explanation is that participants retrospectively reported that during the experiment they came to view the US as progressively less unpleasant. Such habituation would of course affect conditioned fear responding (as indexed by skin conductance responding), but not the US-expectancy ratings. Therefore, in future research, one should attempt to make use of a more aversive US, such as an electric shock (see for example, Vansteenwegen et al., 2006). A second possibility is to change the nature of the CSs used. In previous research it has been found that superior acquisition of psychophysiological conditioned fear responding is observed when the CS being paired with the scream is a picture of a human face (see Hamm, Vaitl, \& Lang, 1989). This suggests that face-scream pairings would allow one to employ less conditioning trials and as such limit the degree of US habituation.

In sum, the present results thus suggest that when a discrete cue is added to the extinction phase without a corresponding context switch, participants are more likely to ascribe the non-occurrence of the US to the extinction cue, thus promoting the development of conditioned inhibition. One potential reason for this result lies in the fact that in the present experiment, the extinction cue was present throughout the extinction and hence always present alongside the presentation of CS1 and CS3. As such, one can argue that participants in groups AAAcue and AAAno cue underwent an explicit conditioned inhibition discrimination procedure. In animal 
research, the cue usually precedes only a portion of CS-noUS presentations, which undermines the development of conditioned inhibition (see e.g., Brooks \& Bouton, 1994).

The present pattern of results further suggest that when extinction is conducted in a different context the extinction cue is more readily viewed as a distinct feature of the extinction context and thus is more likely to acquire an occasion setting function. It should be noted though, that this account is a post hoc explanation of the results and its validation requires further systematic research. Future research is needed to test whether the extinction cue truly functions as an occasion setter by examining - for example -whether the extinction cue's ability to suppress renewal of conditioned responding does show selective transfer to target CSs that have been part in another occasion setting discrimination procedure.

\section{Implications for exposure treatment of psychopathology}

Although one might argue that it is speculative to consider clinical implications of the present pattern of results, given the absence of any clear conditioned skin conductance responding, it is generally thought that conditioned responding requires awareness of the contingency between the CS and US (see e.g., Lovibond \& Shanks, 2002). Even though awareness is not sufficient for the development of a conditioned response, the expectancy ratings remain informative with regard to exposure treatments of psychopathology. Especially, when considering that phobic patients tend to overassociate fear-relevant stimuli and aversive outcomes and that this might be an important factor in the maintenance of their fear (e.g., Wiedemann, Pauli, \& Dengler, 2001). Nevertheless, future experiments should still attempt to demonstrate the effect of extinction cues on return of fear using psychophysiological measures. This type of measure not only provides evidence that fear conditioning actually did take place, but also enables a more direct translation of the obtained results into clinical practice.

Again, the important findings with respect to the expectancy ratings observed are that (i) cues reminding one of the extinction treatment attenuate renewal, but that (ii) transfer of this attenuation effect to other, non-extinguished cues is only observed when no switch in context takes place. The absence of such a transfer after a switch in context hinders the general applicability of such a cue in a therapeutic context. This then would mean that a therapist conducting exposure treatment needs to extinguish the patient's anxiety, or fear, or the motivation to use a given substance to all potential CSs in order for an extinction cue present during treatment to effectively limit renewal (i.e., relapse) after treatment. However, promoting the cue coming to function as a safety signal rather than as an occasion setter would solve such a limitation. At present, however, it is still unclear how to achieve this. Furthermore, if one would succeed at making the extinction cue a conditioned inhibitor, an important danger of such a procedure might be that it prevents the development of extinction to the CS itself, which would make the efficacy of the exposure treatment dependent on the extinction cue. Theoretically, this protection from extinction effect might allow for a full "recovery" of US-expectancy and hence conditioned responding in the absence of the extinction cue (see also Lovibond, Davis, \& O'Flaherty, 2000). Therefore, future research should focus on the development of methods that may promote transfer of the safety cue to other, non-extinguished, stimuli outside the extinction context without such a procedure attenuating extinction to the relevant CSs during treatment.

\section{Acknowledgements}

We would like to thank Debora Vansteenwegen and her colleagues and Joyce van Erp for their contribution to this research paper.

\section{References}

Abramowitz, J. S. (1996). Variants of exposure and response prevention in the treatment of obsessive-compulsive disorder: a meta-analysis. Behavior Therapy, 27(4), 583-600.

Bouton, M. E. (2002). Context, ambiguity, and unlearning: sources of relapse after behavioral extinction. Biological Psychiatry, 52(10), 976-986.

Bouton, M. E. (2004). Context and behavioral processes in extinction. Learning and Memory, 11(5), 485-494.

Brooks, D. C., \& Bouton, M. E. (1993). A retrieval cue for extinction attenuates spontaneous recovery. Journal of Experimental Psychology: Animal Behavior Processes, 19(1), 77-89.

Brooks, D. C., \& Bouton, M. E. (1994). A retrieval cue for extinction attenuates response recovery (renewal) caused by a return to the conditioning context. Journal of Experimental Psychology: Animal Behavior Processes, 20(4), 366-379.

Brooks, D. C., \& Bowker, J. L. (2001). Further evidence that conditioned inhibition is not the mechanism of an extinction cue's effect: a reinforced prevents spontaneous recovery. Animal Learning and Behavior, 29(4), 381-388.

Brooks, D. C., Palmatier, M. I., Garcia, E. O., \& Johnson, J. L. (1999). An extinction cue reduces spontaneous recovery of a conditioned taste aversion. Animal Learning and Behavior, 27(1), 77-88.

Brooks, D. C., Vaughn, J. M., Freeman, A. J., \& Woods, A. M. (2004). An extinction cue reduces spontaneous recovery of ataxic ethanol tolerance in rats. Psychopharmacology, 176(3-4), 256-265.

Collins, B. N., \& Brandon, T. H. (2002). Effects of extinction context and retrieval cues on alcohol cue reactivity among nonalcoholic drinkers. Journal of Consulting and Clinical Psychology, 70(2), 390-397.

Conklin, C. A., \& Tiffany, S. T. (2002). Applying extinction research and theory to cueexposure addiction treatments. Addiction, 97(2), 155-167.

Dibbets, P., Maes, J. H., Boermans, K., \& Vossen, J. M. (2001). Contextual dependencies in predictive learning. Memory, 9(1), 29-38.

Drummond, D. C., Cooper, T., \& Glautier, S. P. (1990). Conditioned learning in alcohol dependence: implications for cue exposure treatment. Addiction, 85(6) 725-743.

Drummond, D. C., \& Glautier, S. (1994). A controlled trial of cue exposure treatment in alcohol dependence. Journal of Consulting and Clinical Psychology, 62(4), 809-817.

Drummond, D. C., Tiffany, S. T., Glautier, S., \& Remington, B. (1995). Cue exposure in understanding and treating addictive behaviours. In D. C. Drummond, S. T. Tiffany, S. Glautier, \& B. Remington (Eds.), Addictive behaviour: Cue exposure theory and practice (pp. 1-17). Oxford, England: John Wiley and Sons.

Foa, E. B., Rothbaum, B. O., \& Furr, J. M. (2003). Augmenting exposure therapy with other CBT procedures. Psychiatric Annals, 33(1), 47-53.

Gunther, L. M., Denniston, J. C., \& Miller, R. R. (1998). Conducting exposure treatment in multiple contexts can prevent relapse. Behaviour Research and Therapy 36(1), 75-91.

Hall, G., \& Honey, R. C. (1989). Contextual effects in conditioning, latent inhibition, and habituation: associative and retrieval functions of contextual cues. Journal of Experimental Psychology: Animal Behavior Processes, 15(3), 232-241.

Hamm, A. O., Vaitl, D., \& Lang, P. J. (1989). Fear conditioning, meaning, and belongingness: a selective association analysis. Journal of Abnormal Psychology, 98(4), 395-406.

Havermans, R. C., \& Jansen, A. T. M. (2003). Increasing the efficacy of cue exposure treatment in preventing relapse of addictive behavior. Addictive Behaviors, 28(5), 989-994.

Holland, P. C. (1983). Occasion-setting in Pavlovian feature positive discriminations In M. L. Commons, R. J. Herrnstein, \& A. R. Wagner (Eds.), Quantitative analyses of behavior: Discrimination processes. New York: Ballinger.

Holland, P. C. (1989). Transfer of negative occasion setting and conditioned inhibition across conditioned and unconditioned stimuli. Journal of Experimental Psychology: Animal Behavior Processes, 15(4), 311-328.

Honey, R. C., Willis, A., \& Hall, G. (1990). Context specificity in pigeon autoshaping. Learning and Motivation, 21(2), 125-136.

Lovibond, P. F., Davis, N. R., \& O'Flaherty, A. S. (2000). Protection from extinction in human fear conditioning. Behaviour Research and Therapy, 38(10), 967-983.

Lovibond, P. F., \& Shanks, D. R. (2002). The role of awareness in Pavlovian conditioning: empirical evidence and theoretical implications. Journal of Experimental Psychology: Animal Behavior Processes, 28(1), 3-26.

Lykken, D. T., \& Venables, P. H. (1971). Direct measurement of skin conductance: a proposal for standardization. Psychophysiology, 8(5), 656-672.

Marks, I. M., Hodgson, R., \& Rachman, S. (1975). Treatment of chronic obsessivecompulsive neurosis by in-vivo exposure: a two-year follow-up and issues in treatment. British Journal of Psychiatry, 127, 349-364.

Mineka, S., Mystkowski, J. L., Hladek, D., \& Rodriguez, B. I. (1999). The effects of changing contexts on return of fear following exposure therapy for spider fear. Journal of Consulting and Clinical Psychology, 67(4), 599-604.

Mystkowski, J. L., Craske, M. G., \& Echiverri, A. M. (2002). Treatment context and return of fear in spider phobia. Behavior Therapy, 33(3), 399-416.

Mystkowski, J. L., Mineka, S., Vernon, L. L., \& Zinbarg, R. E. (2003). Changes in caffeine states enhance return of fear in spider phobia. Journal of Consulting and Clinical Psychology, 71(2), 243-250.

Ost, L. G. (1997). Rapid treatment of specific phobias. In G. C. L. Davey (Ed.), Phobias: A handbook of theory, research and treatment (pp. 227-246). Chichester, England: John Wiley \& Sons. 
Rodriguez, B. I., Craske, M. G., Mineka, S., \& Hladek, D. (1999). Context-specificity of relapse: effects of therapist and environmental context on return of fear. Behaviour Research and Therapy, 37(9), 845-862.

Shea, C. H., \& Wright, D. L. (1995). Contextual dependencies: influence on response latency. Memory, 3(1), 81-95.

Smith, S. M. (1988). Environmental context-dependent memory. In G. M. Davies, \& D. M. Thomson (Eds.), Memory in context: Context in memory (pp. 13-34). Oxford, England: John Wiley and Sons.

Smith, S. M., \& Vela, E. (2001). Environmental context-dependent memory: a review and meta-analysis. Psychonomic Bulletin and Review, 8(2), 203-220.
Thewissen, R., Snijders, S. J. B. D., Havermans, R. C., van den Hout, M., \& Jansen, A. (2006). Renewal of cue-elicited urge to smoke: implications for cue exposure treatment. Behaviour Research and Therapy, 44(10), $1441-1449$.

Vansteenwegen, D., Vervliet, B., Hermans, D., Beckers, T., Baeyens, F., \& Eelen, P. (2006). Stronger renewal in human fear conditioning when tested with an acquisition retrieval cue than with an extinction retrieval cue. Behaviour Research and Therapy.

Wiedemann, G., Pauli, P., \& Dengler, W. (2001). A priori expectancy bias in patients with panic disorder. Journal of Anxiety Disorders, 15(5), 401-412. 